\title{
FIBROUS DYSPLASIA OF ETHMOID SINUS
}

\author{
(A Case Report)
}

\author{
Gp Capt LK KOCHHAR, vsM ${ }^{*}$, Maj SC GUPTA ${ }^{+}$, \\ Lt Col RP MISRA ${ }^{\#}$, Lt Col AK VERMA ${ }^{* *}$, \\ Lt Col B MUKERJEE ${ }^{++}$, Col RN DIWAN ${ }^{\# \#}$
}

\author{
MJAFI 1998; 54 : 61-62
}

KEYWORDS : Fibrous dysplasia; Paranasal sinuses.

\section{Introduction}

F ibrous dysplasia is a rare clinical entity and especially of paranasal sinuses and that too, of ethmoidal region. Very few cases have been reported in literature of fibrous dysplasia of ethmoid sinus. The fibrous dysplasia of this region gradually involves the surrounding area, including other groups of paranasal sinuses and orbit.

\section{Case Report}

A 28-year-old male solider presented with history of gradual bulging of left eye of 5 years duration (Fig 1). Except bulging of left eye, patient did not have any other complaint. Patient gave past history of biopsy of the mass from left maxillary antrum twice through Caldwell-Luc's approach and underwent other battery of tests including CT scan skull. However the biopsy results were inconclusive.

The patient was an average built, well nourished and his other vital parameters were within normal limits. No general and systemic abnormality was detected except bulging of left eye ball in

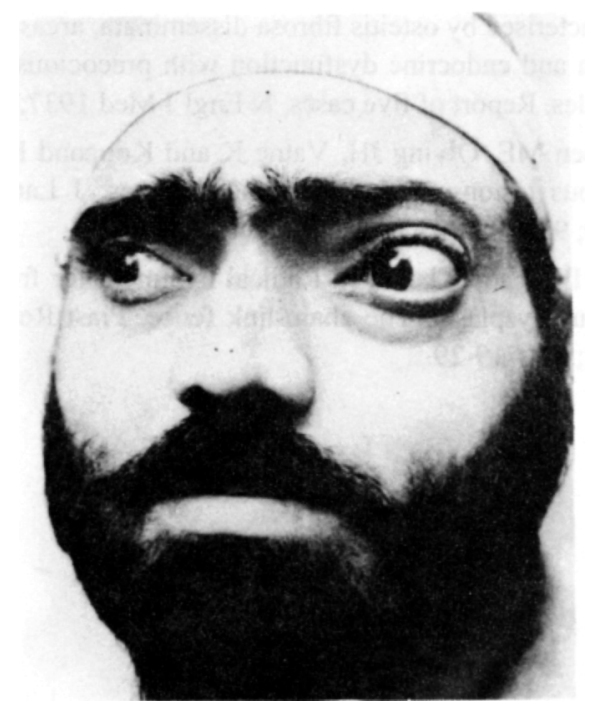

Fig I : antero-lateral direction. Movements of eye were full in all directions. Vision of left eye was normal. On palpation $1 \mathrm{~cm}$ diameter, spherical, non tender bony swelling was felt over the left medial canthus. Hertel's ophthalmometry done preoperatively showed, a proptosis of $8 \mathrm{~mm}$ of left eye ball.

Serum calcium, serum phosphate and alkaline phosphatase were within normal limits. Radioactive iodine uptake showed euthyroid status and thyroid scan showed normal morphology. CT scan of skull (Fig 2) showed a large irregular lesion affecting medial wall of left orbit, left nasal cavity, left pterygoid plate, left ethmoid air cells, sphenoid sinus, maxillary sinus and roof of left orbit. There was expansion of the bone with dense bony texture with soft tissue density within the lesion suggestive of fibrous dysplasia.

He was diagnosed a case of librous dysplasia of left ethmoid air cells extending to other paranasal sinuses and left orbit and was taken up for surgery. Extended Lynch Howarth incision was given. After elevating periosteum a grey mass was seen in the medial half of left orbit extending downward to left maxillary antrum and medially to posterior part of left nasal cavity. The visible portion of the lesion was removed in piecemeal and sent for histopathological examination which revealed it to be fibrous dys-

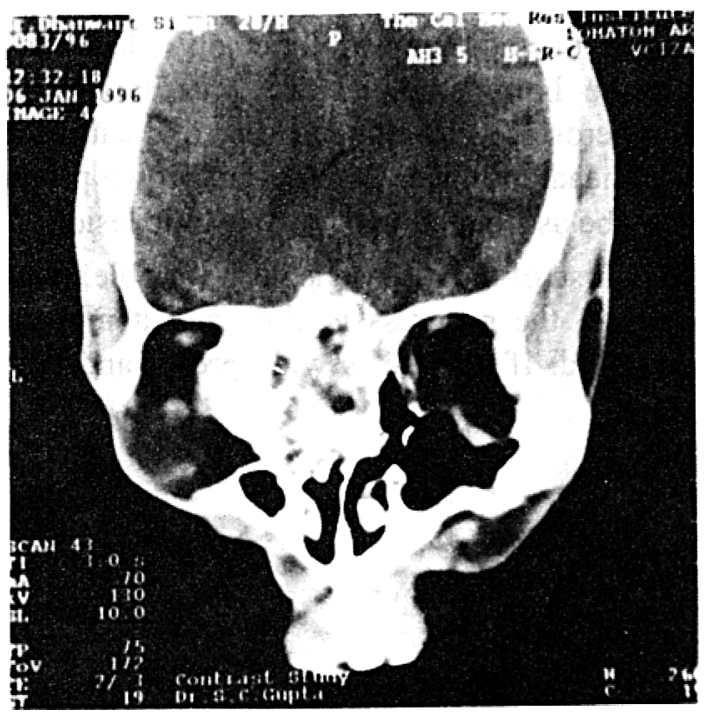

lig. 2:

Senior Adviser \& Head of Dept (ENT). "Graded Specialist (ENT), ${ }^{\sharp}$ Classified Specialist (Ophthal), ${ }^{* *}$ Classified Specialist (Surg \& Neuro ırgery), ${ }^{++}$Classified Specialist (Pathology), ${ }^{* \#}$ Senior Adviser \& CO, Command Path Lab (EC), Alipore, Calcutta 700027. 


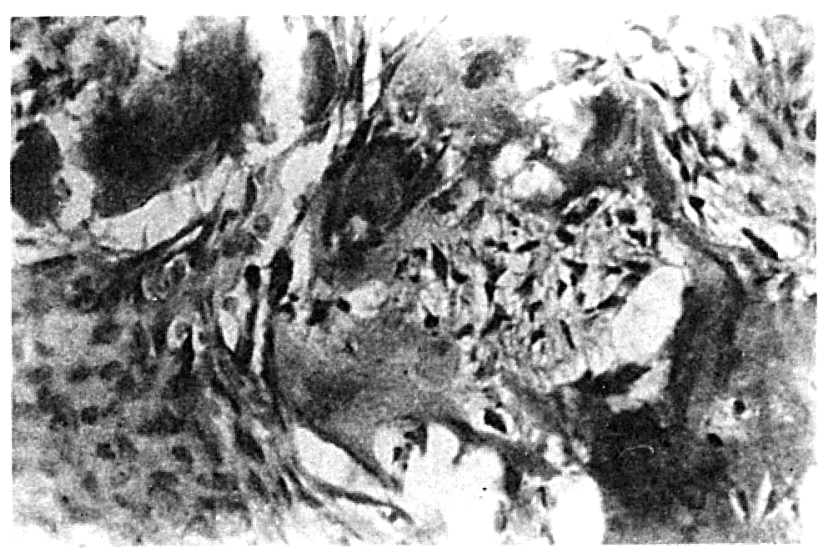

Fig. 3 :

plasia (Fig 3). The patient made a good post-operative recovery and was reviewed after 2 months. $A$ t this time the patient was asymptomatic and Hertel's ophthalmometry revealed a proptosis of only $3 \mathrm{~mm}$. Repeat CT scan at this time also showed the removal of the mass from ethmoid aircells, left orbit and part of maxillary antrum though the sellar region still showed evidence of fibrous dysplasia (Fig 4) of unknown aetiology.

\section{Discussion}

Fibrous dysplasia is a rare disease of unknown aetiology characterised by fibrous tissue replacement of skeleton. It may be mono-ostotic or poly-ostotic. Polyostotic lesion when associated with cutaneous pigmentation and endocrine disorders is known as Albright's Syndrome [1]. Common sites of the disease are long bones of lower limbs and base of skull. Among skull bones, it is the ethmoid bone which is least involved.

It generally begins in childhood and it may progress beyond puberty and through adulthood. Both sexes are equally affected. In the natural course of the disease, in first few years the condition is asymptomatic, often discovered on radiography. Later on it leads to fracture of the bone involved and pressure symptoms. Skull hyperostosis develops at base and causes asymmetry of head and face. Cafe-au-lait brown patches on skin may be associated with poly-ostotic lesion.

The course of the disease is very variable. If disease is localised, the progress is slow and it may remain unrecognised. If disease is widespread, and develops

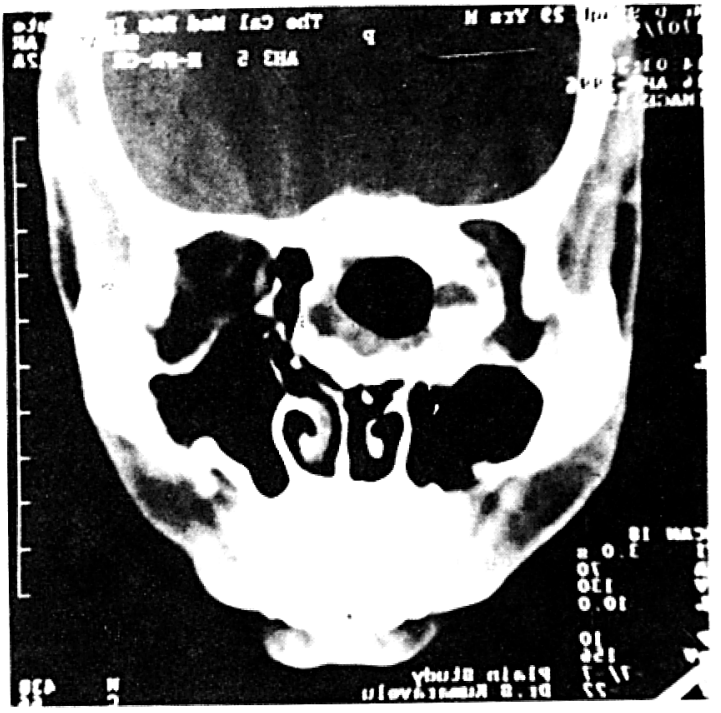

Fig. 4 :

early in life then the progression is marked and deformity is severe. Malignant degeneration does not occur in fibrous dysplasia unless the lesion is subjected to irradiation. Boysen et al and Chir and Chen have recommended that no treatment is required if the patient is asymptomatic and without any facial deformity $[2,3]$. But once the pressure symptoms, like proptosis, diplopia, defective vision and facial deformity occurs, radical resection with reconstruction is recommended. In the present case the visible portion of fibrous dysplasia mass was removed because radical resection was not possible because of extensive spread of the disease into sphenoid sinus and sellar region.

\section{REFERENCES}

1. Albright F, Butler AM, Hampton AO and Smith P. Syndrome characterised by osteitis fibrosa disseminata, areas of pigmentation and endocrine dysfunction with precocious puberty in females. Report of five cases, N Engl J Med 1937; 216: 727.

2. Boysen ME, Olving JH, Vatne K and Koppand HS. Fibrous osseous lesions of the craniofacial bones. J Laryngol Otol 1979; 93: 793-807.

3. Chir IRM and Chen YR. Radical treatment for fronto-orbital fibrous dysplasia. The chain-link fence. Plast Reconstr Surg 1981: 67: 719-29. 